\title{
Assessment of radioactivity contents in bedrock groundwater samples from the northern region of Saudi Arabia
}

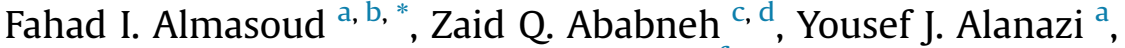 \\ Mayeen Uddin Khandaker ${ }^{e}$, M.I. Sayyed ${ }^{\mathrm{f}}$ \\ a Nuclear Science Research Institute (NSRI), King Abdulaziz City for Science and Technology (KACST), P.0.Box 6086, Riyadh, 11441, Saudi Arabia \\ ${ }^{\mathrm{b}}$ Department of Soil Sciences, College of Food and Agricultural Sciences, King Saud University, P.O. Box 2460, Riyadh, 11451, Saudi Arabia \\ c Physics Dept., Faculty of Science, Yarmouk University, Irbid, 211-63, Jordan \\ d College of Applied Medical Sciences, King Saud Bin Abdulaziz University for Health Sciences, Al-Ahsa, Saudi Arabia \\ e Center for Biomedical Physics, School of Healthcare and Medical Sciences, Sunway University, 47500, Bandar Sunway, Selangor, Malaysia \\ ${ }^{\mathrm{f}}$ Department of Physics, Faculty of Science, University of Tabuk, Tabuk, Saudi Arabia
}

\section{H I G H L I G H T S}

- Gross $\alpha$ and $\beta$ radioactivity in groundwater samples has been investigated in northern part in KSA

- The contributions of $U$ and Ra alpha emitters to gross $\alpha$ radioactivity were discussed.

- The ratios of the measured $\beta$ emitters to gross $\beta$ radioactivity were discussed.

- The ratios of ${ }^{228} \mathrm{Ra} /{ }^{226} \mathrm{Ra},{ }^{226} \mathrm{Ra} /{ }^{238} \mathrm{U}$, and ${ }^{234} \mathrm{U} /{ }^{238} \mathrm{U}$ in groundwater were investigated.

\section{A R T I C L E I N F O}

\section{Article history:}

Received 10 June 2019

Received in revised form

7 October 2019

Accepted 20 October 2019

Available online $\mathrm{xxx}$

Handling Editor: Martine Leermakers

\section{Keywords:}

Bedrock groundwater

Gross $\alpha / \beta$ radioactivity

NORM

Liquid scintillation counting

Alpha spectrometry

Radioactive disequilibrium
G R A P H I C A L A B S T R A C T

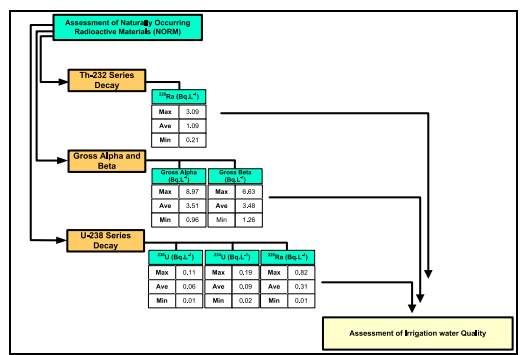

\begin{abstract}
A B S T R A C T
Recognizing the vast uses of water in human life, the presence of $\alpha$ and $\beta$ particles emitting radionuclides in groundwater of northern Saudi Arabia has been evaluated as a means of water quality assessment of the region. A liquid scintillation counting technique was used to determine the gross $\alpha / \beta$, and ${ }^{228} \mathrm{Ra}$ radioactivities in water samples, while the radioactivity concentrations of ${ }^{234,238} \mathrm{U}$ and ${ }^{226} \mathrm{Ra}$ were determined using alpha spectrometry after the separation process.

Present results show that all water samples contain a higher level of gross $\alpha$ and $\beta$ radioactivity than the WHO recommended limits; the average gross $\alpha$ activity is about 7 times greater than the limit value of $0.5 \mathrm{~Bq} \mathrm{~L}^{-1}$, while the average gross $\beta$ activity value is about 3.5 times greater than the limit value of 1 $\mathrm{Bq} \mathrm{L}{ }^{-1}$. Correlations of TDS and $\mathrm{pH}$ with gross $\alpha$ and $\beta$ radioactivity in the studied samples were investigated. The activity ratio of the measured $U$ and Ra alpha emitters to the gross $\alpha$ radioactivity and the ratio of the measured $\beta$ emitters to gross $\beta$ radioactivity were also discussed. Furthermore, interesting information on thorium abundance and radioactive disequilibrium in $U$ series were observed by studying the activity ratio of ${ }^{228} \mathrm{Ra} /{ }^{226} \mathrm{Ra},{ }^{226} \mathrm{Ra} /{ }^{238} \mathrm{U}$, and ${ }^{234} \mathrm{U} /{ }^{238} \mathrm{U}$. Although these samples are not directly used for human being drinking, and mainly used in irrigation, the higher gross $\alpha / \beta$ radioactivity may cause
\end{abstract}

\footnotetext{
* Corresponding author. Nuclear Science Research Institute (NSRI), King Abdulaziz City for Science and Technology (KACST), P.O. Box 6086, Riyadh, 11441, Saudi Arabia.

E-mail address: fmasaud@kacst.edu.sa (F.I. Almasoud).
} 